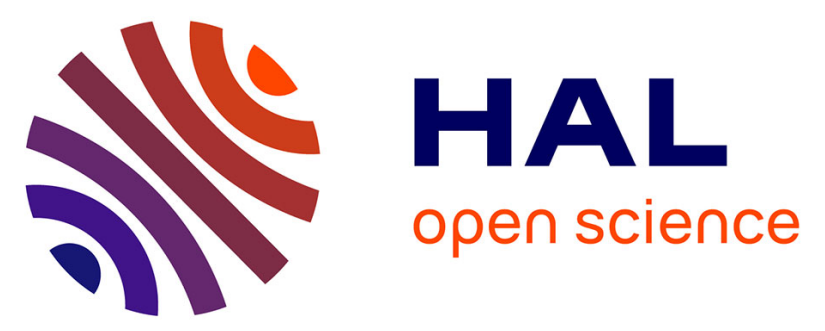

\title{
Experience with the use of a hemostatic powder in 152 patients undergoing urgent endoscopy for gastrointestinal bleeding
}

\author{
Aymeric Becq, Charles Houdeville, My-Linh Tran Minh, Nils Steuer, David
} Danan, Marie Anne Guillaumot, Einas Abou Ali, Maximilien Barret, Aurélien Amiot, Nicolas Carbonell, et al.

\section{To cite this version:}

Aymeric Becq, Charles Houdeville, My-Linh Tran Minh, Nils Steuer, David Danan, et al.. Experience with the use of a hemostatic powder in 152 patients undergoing urgent endoscopy for gastrointestinal bleeding. Clinics and Research in Hepatology and Gastroenterology, 2021, 45 (5), pp.101558. 10.1016/j.clinre.2020.10.003 . hal-03448654

\section{HAL Id: hal-03448654 https://hal.sorbonne-universite.fr/hal-03448654}

Submitted on 25 Nov 2021

HAL is a multi-disciplinary open access archive for the deposit and dissemination of scientific research documents, whether they are published or not. The documents may come from teaching and research institutions in France or abroad, or from public or private research centers.
L'archive ouverte pluridisciplinaire HAL, est destinée au dépôt et à la diffusion de documents scientifiques de niveau recherche, publiés ou non, émanant des établissements d'enseignement et de recherche français ou étrangers, des laboratoires publics ou privés. 


\section{Clinics and Research in Hepatology and Gastroenterology EXPERIENCE WITH THE USE OF A HEMOSTATIC POWDER IN 152 PATIENTS UNDERGOING URGENT ENDOSCOPY FOR GASTROINTESTINAL BLEEDING --Manuscript Draft--}

\begin{tabular}{|c|c|}
\hline Manuscript Number: & CLINRE-D-20-00905R1 \\
\hline Article Type: & Original article \\
\hline Corresponding Author: & $\begin{array}{l}\text { Aymeric Becq, M.D. } \\
\text { Hopital Saint-Antoine } \\
\text { Paris, FRANCE }\end{array}$ \\
\hline First Author: & Aymeric Becq, M.D. \\
\hline \multirow[t]{14}{*}{ Order of Authors: } & Aymeric Becq, M.D. \\
\hline & Charles Houdeville, MD \\
\hline & My-Linh Tran Minh, MD \\
\hline & Nils Steuer, MD \\
\hline & David Danan, MD \\
\hline & Marie Anne Guillaumot, MD \\
\hline & Einas Abou Ali, MD \\
\hline & Maximilien Barret, MD, PhD \\
\hline & Aurélien Amiot, MD, PhD \\
\hline & Nicolas Carbonell, MD \\
\hline & Philippe Marteau, MD, PhD \\
\hline & Ulriikka Chaput, MD \\
\hline & Xavier Dray, MD, PhD \\
\hline & Marine Camus \\
\hline Abstract: & $\begin{array}{l}\text { Background and Study Aims } \\
\text { In the recent years, topical hemostatic powders have been used for the management } \\
\text { of upper gastrointestinal bleeding. The aim of this study was to report on the use of an } \\
\text { hemostatic powder (Hemospray }(\text { ), outside regular hours, by on-call endoscopists } \\
\text { during urgent endoscopic procedures. } \\
\text { Material and methods } \\
\text { In this retrospective multicenter cohort study, consecutive patients having undergone } \\
\text { an urgent endoscopy with the use of Hemospray } 8 \text { from November } 2015 \text { to December } \\
2018 \text { in the Paris and suburbs area were included. We collected clinical, biological and } \\
\text { endoscopic variables. The outcomes such as the recurrence, repeat endoscopy and } \\
\text { hemostatic treatment need, complications and survival were also collected. } \\
\text { Results } \\
\text { A total of } 152 \text { patients (mean } 65 \text { years old, } 70.4 \% \text { male) were included. Amongst the } \\
31 \text { endoscopists, } 11 \text { were "more experienced", and performed } 48 \% \text { of the } \\
\text { endoscopies. The most common causes of bleeding were peptic ulcer ( } 47.7 \% \text { ), } \\
\text { malignancy (22.2\%) and esophagitis (12.4\%). Most bleedings originated from the } \\
\text { upper GI tract (95.0\%). Hemospray }{ }^{\circledR} \text { was used as a salvage therapy in } 60.8 \% \text { of } \\
\text { cases. Other hemostatic techniques were used in } 52.9 \% \text { of cases. Immediate bleeding } \\
\text { cessation was noted in } 79.0 \% \text { of cases, recurrence in } 39.9 \% \text { of cases, and } 26.4 \% \text { of } \\
\text { patients benefited from a repeat endoscopic hemostasis. } 34 \text { (23.0\%) patients required } \\
\text { a non-endoscopic treatment. At day } 30, \text { the survival rate was } 71.6 \% \text {. One complication }\end{array}$ \\
\hline
\end{tabular}




\begin{tabular}{|l|l|}
\hline & was reported (perforation). \\
& Conclusions \\
& $\begin{array}{l}\text { Hemostatic powder application by on-call endoscopists outside regular hours is } \\
\text { technically feasible, but comes with a high risk of rebleeding in severely ill patients. }\end{array}$ \\
\hline Suggested Reviewers: & $\begin{array}{l}\text { Samuel Giday, MD } \\
\text { samgiday@gmail.com } \\
\text { Leader in the field of endoscopy }\end{array}$ \\
\hline $\begin{array}{ll}\text { lan Gralnek } \\
\text { ian_gr@clalit.org.il } \\
\text { Leader in the field of gastro intestinal bleeding }\end{array}$ \\
\hline $\begin{array}{l}\text { John Morris } \\
\text { john.morris@ggc.scot.nhs.uk } \\
\text { Leader in the field of endoscopy }\end{array}$ \\
\hline Opposed Reviewers: & \begin{tabular}{l} 
\\
\hline
\end{tabular} \\
\hline
\end{tabular}




\title{
EXPERIENCE WITH THE USE OF A HEMOSTATIC POWDER IN 152 PATIENTS UNDERGOING URGENT ENDOSCOPY FOR GASTROINTESTINAL BLEEDING
}

\author{
Aymeric Becq ${ }^{1}$, Charles Houdeville ${ }^{1}$, My-Linh Tran Minh ${ }^{2}$, Nils Steuer ${ }^{3}$, David Danan ${ }^{4}$, Marie \\ Anne Guillaumot ${ }^{5}$, Einas Abou Ali ${ }^{5}$, Maximilien Barret ${ }^{5}$, Aurélien Amiot ${ }^{6}$, Nicolas Carbonell ${ }^{1}$, \\ Philippe Marteau ${ }^{1}$, Ulriikka Chaput ${ }^{1}$, Xavier Dray $^{1}$, the Parisian On-call Endoscopy Team (POET) \\ and Marine Camus ${ }^{1}$. \\ 1. Sorbonne Université, Endoscopy Unit, AP-HP, Hôpital Saint-Antoine, F-75012 Paris, France \\ 2. Saint Louis Hospital, Assistance Publique Hôpitaux de Paris (APHP), Paris, France \\ 3. Paris 13 University, Avicennes Hospital, Assistance Publique Hôpitaux de Paris (APHP), \\ Bobigny, France
}

4. Paris V Descartes University, HEGP, Assistance Publique Hôpitaux de Paris (APHP), Paris, France

5. Paris V Descartes University, Cochin Hospital, Assistance Publique Hôpitaux de Paris (APHP), Paris, France

6. Paris 12 University, Henri Mondor Hospital, Assistance Publique Hôpitaux de Paris (APHP), Créteil, France

* Other Parisian On-call Endoscopy Team (POET) members: Cyriaque Bon, Benoît Bordacahar, Bertrand Brieau, Charlotte Delattre, Johann Dreanic Julien Kirchgesner, Cécilia Landman, Anne Laurain, Guillaume Le Gall, Romain Leenhardt, Sara Lemoinne, Marie Lequoy, Nelson Lourenco, Chloé Martineau, Frédérick Moryoussef, Jean-Charles Nault, Jeanne Netter, Violaine Ozenne, Anna Pellat, Olivia Pietri, Pierrre Rompteaux, Adrien Sportes, Aziz Zaanan

Correspondence to: Aymeric Becq, MD, MSc

Endoscopy department, Saint Antoine Hospital, Paris, France

184 Rue du Faubourg Saint Antoine, Paris, 75012

Tel: 01.71.97.08.43; Fax: 01.49.28.29.70

E-mail: aymeric.becq@aphp.fr 
Specific author contributions: $\mathrm{AB}, \mathrm{CH}, \mathrm{MC}$ : Conception and study design, data collection and analysis, drafting and revising of the manuscript. MLTM, NS, DD, MAG, EAA, MB, AA, NC, PM, UC, XD: analysis, drafting and revising of the manuscript.

Conflicts of interest:

Dr Marine Camus is a consultant for Boston Scientific and Cook Medical.

Dr Xavier Dray has acted as a consultant for Alfasigma, Bouchara Recordati, Boston Scientific, Fujifilm, Medtronic, and Pentax. Author Xavier Dray is also cofounder and shareholder of company Augmented Endoscopy.

Dr Maximilien Barret is a consultant for Norgine and Medtronic.

Drs Aymeric Becq, Charles Houdeville, My-Linh Tran Minh, Nils Steuer, David Danan, Marie Anne Guillaumot, Einas Abou Ali, Aurélien Amiot, Nicolas Carbonell, Philippe Marteau and Ulriikka Chaput have no conflicts of interest or financial ties to disclose. 


\section{Background and Study Aims}

In the recent years, topical hemostatic powders have been used for the management of upper gastrointestinal bleeding. The aim of this study was to report on the use of an hemostatic powder $\left(\right.$ Hemospray $\left.{ }^{\circledR}\right)$, outside regular hours, by on-call endoscopists during urgent endoscopic procedures.

\section{Material and methods}

In this retrospective multicenter cohort study, consecutive patients having undergone an urgent endoscopy with the use of Hemospray ${ }^{\circledR}$ from November 2015 to December 2018 in the Paris and suburbs area were included. We collected clinical, biological and endoscopic variables. The outcomes such as the recurrence, repeat endoscopy and hemostatic treatment need, complications and survival were also collected.

Results

A total of 152 patients (mean 65 years old, 70.4\% male) were included. Amongst the 31 endoscopists, 11 were "more experienced", and performed $48 \%$ of the endoscopies. The most common causes of bleeding were peptic ulcer (47.7\%), malignancy (22.2\%) and esophagitis (12.4\%). Most bleedings originated from the upper GI tract (95.0\%). Hemospray ${ }^{\circledR}$ was used as a salvage therapy in $60.8 \%$ of cases. Other hemostatic techniques were used in $52.9 \%$ of cases. Immediate bleeding cessation was noted in $79.0 \%$ of cases, recurrence in $39.9 \%$ of cases, and $26.4 \%$ of patients benefited from a repeat endoscopic hemostasis. 34 (23.0\%) patients required a non-endoscopic treatment. At day 30, the survival rate was $71.6 \%$. One complication was reported (perforation).

\section{Conclusions}

Hemostatic powder application by on-call endoscopists outside regular hours is technically feasible, but comes with a high risk of rebleeding in severely ill patients.

Keywords: Hemospray ${ }^{\circledR}$, hemostatic powder, digestive bleeding, gastrointestinal hemorrhage 


\author{
ABBREVIATIONS \\ - GIB: Gastrointestinal bleeding \\ - UGIB: Upper gastrointestinal bleeding \\ - PUD: Peptic ulcer disease \\ - POET: Parisian On-call Endoscopy Team
}




\section{INTRODUCTION}

Acute gastrointestinal bleeding (GIB) is a common condition, associated with a significant morbidity and mortality $(1,2)$. Mortality rates have been reported ranging from 3 to $14 \%$, depending on the age, co-morbidities, clinical status, cause of bleeding $(1,2)$. Upper gastrointestinal bleeding (UGIB) accounts for over $80 \%$ of all GIB. Guidelines on the management of variceal and non-variceal UGIB have been published $(3,4)$. Endoscopic hemostasis is the cornerstone of the management of GIB and relies on injection, thermal and mechanical therapies (5). Injection therapy (epinephrine, sclerosing agents, and glue), thermocoagulation (including plasma argon coagulation and bipolar electrocautery), as well as hemostatic clips and band ligation have been shown to be effective methods in this setting (6-9). However, they are not always efficient and offer limited success in cases of large bleeding areas (i.e. malignancy) (10).

In the more recent years, topical hemostatic powders such as Hemospray ${ }^{\circledR}$ (TC-325; Cook Medical, Winston-Salem, NC, USA) have been tested on porcine models, then used for the management of UGIB in humans (10-14). Hemospray ${ }^{\circledR}$ is an inorganic, absorbent powder, which upon contact with the moisture of an active bleeding, becomes coherent, creating a mechanical barrier. It also activates platelet aggregation and possibly concentrates coagulation factors (10). The resulting coagulum typically sloughs off within 24 hours (15). Hemospray ${ }^{\circledR}$ has received clearance in multiple countries, specifically in Europe and has recently been FDA approved $(11,16)$. Only a few number of studies have been published on Hemospray ${ }^{\circledR}$, showing it to be technically feasible and a viable option as primary or salvage hemostatic treatment of UGIB (17-19).

The goal of our study was to report on the real-life use of Hemospray ${ }^{\circledR}$, in the setting of urgent endoscopies, performed by mobile on-call endoscopists, outside regular hours, in multiple Parisian teaching hospitals.

\section{PATIENTS AND METHODS}

We performed a retrospective descriptive multicenter cohort study to investigate the use of Hemospray ${ }^{\circledR}$ during emergencies, by on-call endoscopists. This study was approved by the local ethics committee. IRB approval was not required for this study. Patients' data was de-identified. 
Outside regular hours (nights and week-ends), urgent endoscopy procedures are performed by an on-call endoscopist in over 20 Parisian teaching hospitals, covering a 5 million inhabitant area. All endoscopists are senior attending physicians, fully trained in all the hemostatic techniques. All have received hands-on training sessions on the use of Hemospray ${ }^{\circledR}$. A taxicab is used to go from one hospital to another. The endoscopist is based at Saint-Antoine Hospital where all the equipment is stored. The on call team and equipment is transported by taxicab to perform hemostatic technics such as clipping, epinephrine injection, band ligation, thermocoagulation and hemostatic powder application (figure 1).

We included consecutive patients having undergone an urgent endoscopy with the use of Hemospray ${ }^{\circledR}$ from November 2015 to December 2018. The indication and treatment decision making was at the discretion of the endoscopist. Hemospray ${ }^{\circledR}$ was applied using the standard seven-French catheter with its tip a few centimeters from the bleeding source. The endoscopist was assisted by a nurse and performed bedside endoscopies in intensive care units with a portable endoscopy processor (Tele Pack X GI, Karl Storz SE \& Co. KG, Tuttlingen, Germany), nontherapeutic gastroscopes (Karl Storz Silver Scope - 13821 PKSK/NKSK, Karl Storz SE \& Co. KG, Tuttlingen, Germany), and a portable electrosurgical unit (ERBE - VIO100C, Erbe Elektromedizin $\mathrm{GmbH}$, Tuebingen, Germany). The procedures were all performed with general anesthesia, after patient intubation, given the high risk of aspiration in UGIB secondary to bloodfilled esophagus and/or stomach, or because in these urgent settings patients are not always with empty stomach as they may have recently eaten or drank. Salvage therapy was defined as the application of Hemospray ${ }^{\circledR}$ for persistent bleeding after failure of other hemostatic modalities either during the same endoscopic procedure or after failure of previous endoscopic attempts. Immediate hemostasis was defined as the absence of ongoing visible active bleeding after Hemospray ${ }^{\circledR}$ application. Recurrence was defined as the requirement of a subsequent hemostatic treatment, meaning either a repeat endoscopic treatment and/or a non-endoscopic treatment (arterial embolization, surgery, radiation therapy) within 30 days.

We collected clinical data. Data regarding the hemorrhagic event was also collected. History of recent endoscopy in the 30 days prior to the one performed by the on-call endoscopist with use of Hemospray ${ }^{\circledR}$, and hemostatic treatment requirement was collected. Endoscopic findings were 


\section{RESULTS}

In the span of the 3 years of the study period, 2840 endoscopies were performed during nonworking hours for suspected bleeding, with hemostatic treatment in 1143 of cases (40.2\%). Hemospray ${ }^{\circledR}$ was used in $13.4 \%$ of all procedures with hemostatic treatment, accounting for $11 \%$ of endoscopies performed for hemostatic purposes in 2016, 8\% in 2017 and 11\% in 2018. During the study period, 152 patients underwent 153 endoscopic procedures in the setting of acute GIB with Hemospray ${ }^{\circledR}$ application. Four patients were excluded due to missing follow-up data (4) (flow chart). These endoscopies were performed by 31 different endoscopists. Amongst these endoscopists, 11 were 'less experienced' and performed 73 of the 153 endoscopies (48\%).

The mean age of the patients was $65.0 \pm 12.2$ years. $70.4 \%$ of patients were male and 61 patients $(40.1 \%)$ were on an antiplatelet and/or anticoagulant medication. Sixty-four patients $(42.1 \%)$ required a vasopressive drug and $142(93.4 \%)$ blood transfusion (table 1).

Forty-six (30.1\%) had endoscopic procedures within the 30 days prior, 26 (56.5\%) of which received hemostatic treatment. The most common causes of bleeding were peptic ulcer disease (PUD) $(47.7 \%)$, bleeding tumors $(22.2 \%)$ and esophagitis (12.4\%). Amongst the nine patients with 
post-endoscopy bleeding, five were secondary to a sphincterotomy. One patient had an aortoenteric fistula. Most bleedings were localized in the upper GI tract (95.0\%) and were active (95.4\%). Regarding the four patients with non-active bleeding, two had a post-sphincterotomy bleed with a clot seen at the level of the papilla. Hemospray ${ }^{\circledR}$ was used as a primary therapy in 60 cases $(39.2 \%)$ and as a salvage therapy in 93 cases $(60.8 \%)$. The use of Hemospray ${ }^{\circledR}$ as a primary or salvage therapy was similar between "less" and "more" experienced endoscopists (38\% and $40 \%$ as a primary therapy, and 62 and $60 \%$ as a salvage therapy, respectively) (figure 2). Other hemostatic techniques were used in 81 cases $(52.9 \%)$. Immediate bleeding cessation was noted in 121 cases $(79.0 \%)$. Use of 2 Hemospray ${ }^{\circledR}$ kits was required in one patient $(0.7 \%)$. Hemospray ${ }^{\circledR}$ application was challenging in five cases (3.3\%) (table 2). Among the patients with persistent bleeding, $7(43.7 \%)$ had received Hemospray ${ }^{\circledR}$ as a primary therapy and $9(56.3 \%)$ as a salvage therapy. Among the patients with bleeding, 41 (33.9\%) had received Hemospray ${ }^{\circledR}$ as a primary therapy and $80(66.1 \%)$ as a salvage therapy (figure 3 ).

Four patients were lost to follow-up. Seventy-one patients (48.0\%) required 88 repeat endoscopic procedures for suspected recurrence. A repeat endoscopy was required in 37 patients before day 3, in 17 patients before day 30, and in 17 patients before day 3 and a second time before day 30 . Thirty-nine patients (26.4\%) required a repeat hemostatic treatment (48 endoscopies) (table 3). Thirty-four $(23.0 \%)$ patients required a non-endoscopic hemostatic treatment such as arterial embolization (9.5\%), surgery (8.8\%), arterial embolization followed by surgery $(2.7 \%)$ and radiation therapy $(2.0 \%)$. Overall, 59 (39.9\%) patients had a recurrence requiring endoscopic and/or non-endoscopic hemostatic treatment. Fourteen (9.5\%) patients required both endoscopic and non-endoscopic hemostatic treatment. One perforation was reported. Verification of the patients' records showed the diagnosis was made by Computed Tomography, 48 hours after the endoscopy, because of worsening clinical condition. Based on the endoscopy report, the patient had a deep peptic ulcer and there was no suspicion of perforation prior or during the endoscopy. At day 30, 106 patients (71.6\%) had survived (table 3). Finally, 23\% and 33\% of patients with and without bleeding cessation respectively did not survive after 30 days of follow-up (Odds Ratio 0.69, 95\% Confidence interval [0.21; 2.63], Fisher's exact test, $p=0.55$ ) (Figure 4). Immediate hemostasis was achieved in 121 (79\%) patients, amongst which $40.9 \%$ (49 patients) did not require further treatment (endoscopic or non-endoscopic) and survived at 30 days. Overall, 
$57(37.5 \%)$ of the 152 patients did not require further treatment (endoscopic or non-endoscopic) and survived at 30 days, regardless of initial bleeding cessation.

\section{DISCUSSION}

In this study, we report on the real life use of the hemostatic powder Hemospray ${ }^{\circledR}$, in the setting of urgent endoscopic procedures performed outside working hours, by mobile on-call endoscopists. Hemospray ${ }^{\circledR}$ was mostly used for upper GIB (95.0\%), nearly half of which were due to PUD $(47.7 \%)$. Hemospray ${ }^{\circledR}$ was used as salvage therapy in $60.8 \%$ of cases. During follow up, $39.9 \%$ had a recurrence. At 30 days of follow-up, the mortality rate was $28.4 \%$.

The use of Hemospray ${ }^{\circledR}$ by our group was stable after becoming available and did not increase with the endoscopists experience. It's use accounts for $10 \%$ of all our cases. It should however be noted that one third of our patients had a prior procedure, nearly two thirds benefited from Hemospray ${ }^{\circledR}$ as a salvage therapy, and that these endoscopies were performed in an urgent setting, in non-dedicated units.

Our study adds to the existing body of literature regarding the use of Hemospray ${ }^{\circledR}$. First, our study serves to show that Hemospray ${ }^{\circledR}$ application is user friendly, consistent with previously published data. The application was challenging in five cases (3.3\%), due to difficult anatomy, scope position and/or obstruction of the catheter. Second, previous studies have reported on the efficacy of Hemospray ${ }^{\circledR}$ application in acute GIB (17-21). The largest study to this day, published in 2019 by Alzoubaidi et al., included 314 patients. The immediate efficacy rate was $89.5 \%$. The recurrence rate amongst these patients was 10.3\%. The 30-day all-cause mortality was 20.0\% (63 of 314 patients) (20). A meta-analysis by Faccuirusso et al. including 1063 patients showed an immediate hemostasis rate of $93.5 \%$, a 30 day recurrence rate of $16.9 \%$, and an all-cause mortality rate of $7.6 \%$ (22). In our study, the immediate efficacy rate was $79 \%$, the recurrence rate was $39.9 \%$, and $28.4 \%$ of patients did not survive at day 30 . The plausible reasons for these differences are many. In our study, $92 \%$ of patients had comorbidities, and $42.1 \%$ required vasopressive support. The mean hemoglobin level was very low $(7 \mathrm{~g} / \mathrm{dL}), 93.4 \%$ were transfused, $40.1 \%$ were on an antiplatelet and/or anticoagulant medication, and $17 \%$ had prior endoscopic hemostatic treatment 
in the last 30 days. Furthermore, endoscopies were performed in difficult conditions: nondedicated units, overnight or during weekends.

A majority of our patients with bleeding cessation had Hemospray ${ }^{\circledR}$ as salvage therapy (66.1\%). Amongst the 16 patients with ongoing bleeding, Hemospray ${ }^{\circledR}$ as primary or salvage therapy did not seem to differ ( 7 of the 60 patients with Hemospray ${ }^{\circledR}$ as primary therapy vs. 9 of the 93 patients with Hemospray ${ }^{\circledR}$ as salvage therapy). We do not believe, based on these results, that Hemospray ${ }^{\circledR}$ should be specifically used as salvage therapy. In some cases, Hemospray ${ }^{\circledR}$ would naturally appear as the first and only choice of treatment (i.e. extensive esophagitis, large tumors), and it seems the rate of ongoing bleeding would not be higher. However, given the cost of this treatment, future studies should specifically assess whether or not it is a cost-effective treatment or not, especially given the likely lower efficiency as a primary therapy.

There was no statistical difference between patients with or without bleeding cessation in terms of mortality rate at day 30 (23 vs $33 \%$, p-value: 0.55 ). This was unsurprising as severely ill patients likely die of other causes, especially those with bleeding cessation, as shown in a previously published study (22).

Finally, after other hemostatic techniques had failed, or were judged inappropriate, Hemospray ${ }^{\circledR}$ yielded an immediate bleeding cessation in 121 patients, $40.5 \%$ of which did not require further intervention and had survived at 30 days of follow-up. Given the temporary hemostatic effect of Hemospray ${ }^{\circledR}$, these results suggest that this technique can be a positive step in stopping an acute bleeding. However, the rebleeding $(41.3 \%, 50 / 121)$ and mortality $(22.3 \%, 27 / 121)$ rates were significant in these patients. We believe that when Hemospray ${ }^{\circledR}$ has been beneficial at first, close monitoring should be implemented to avoid delay of further non-endoscopic hemostatic treatment if needed.

All in all, Hemospray is mostly used as salvage therapy in UGIB, when other techniques have failed, but can also be used as a first line hemostatic treatment when appropriate. Hemospray application should be considered as a temporary treatment, and as being a potential bridge to a non-endoscopic treatment in some cases.

Guidelines recommend the use of Hemospray ${ }^{\circledR}$ in active non-variceal upper GIB. In this study, Hemospray ${ }^{\circledR}$ was mainly performed in patients with upper GIB (95.0\%). In addition, it was used on active bleeding in $95.4 \%$ of cases. Amongst the four patients with non-active bleeding, two had 

In the two other cases (gastric ulcerations with minor stigmata of recent hemorrhage), using Hemospray ${ }^{\circledR}$ was not appropriate. Studies have described the use of Hemospray ${ }^{\circledR}$ in various causes of lower GIB, with high rates of immediate hemostasis $(10,23,24)$. Interesting results have been published in severe diverticular bleeding with immediate hemostasis in a series of ten patients, with no recurrence (24). In our experience, Hemospray ${ }^{\circledR}$ was used for lower GIB (malignancy, varices, ulcer, ischemia) in nine patients. However, there is insufficient data to suggest its routine use in this setting.

In previously published studies, Hemospray ${ }^{\circledR}$ was mainly used in GIB secondary to peptic ulcers, malignancies and post-endoscopy $(11,19)$. Our study shows a different clinical practice. Although Hemospray ${ }^{\circledR}$ was used first in PUD and second in malignancy cases, a significant portion of applications were for esophagitis and post-endoscopy bleeding. In addition, it was used in five patients for esophageal variceal bleeding. Several studies have reported on the use of Hemospray ${ }^{\circledR}$ in variceal GIB. In a review dating from 2015, hemostasis was achieved in $100 \%$ of nine cases of variceal GIB (10). A randomized controlled trial including 86 patients compared early hemostatic powder application followed by early elective endoscopy to early elective endoscopy only. The rate of rescue endoscopy was significantly lower in the hemostatic powder group (12\% vs $30 \%$, $\mathrm{p}=0.034$ ) (25) and the survival was higher ( $30 \%$ vs $7 \% \mathrm{p}=0.006$ ). Finally, in our cohort, Hemospray ${ }^{\circledR}$ was used once in a case of an eso-aortic fistula, which was not known at the time.

Complications of Hemospray ${ }^{\circledR}$ are infrequent. We report one case of perforation. The likelihood of Hemospray ${ }^{\circledR}$ application being the cause of this perforation is difficult to establish but probably low. This is consistent with previously published data and concurs with the safe profile of Hemospray ${ }^{\circledR}$. In the study by Alzoubaidi et al., there were no complications (20). In the review by Chen et al. including 243 cases, 5 complications were reported (10): pain, splenic infarct (unclear if related), transient biliary obstruction (post sphincterotomy bleeding), and hemoperitoneum (unclear if related). In theory, there is a risk of vascular embolization, bowel perforation, and bowel obstruction. Embolization has however never been described. Caution is warranted in case of a thin wall at risk for perforation, and near the ampulla because of the risk of biliary obstruction. 
Several limitations of our study can be outlined. First, this study was retrospective. This was a multicenter study adding to the difficulty in collecting data retrospectively, specifically regarding follow-up. Second, no consensus regarding the criteria used for decision-making (procedure indication and per endoscopy treatment) was established prior to the study. However, this study reports real-life use of Hemospray ${ }^{\circledR}$ during non-working hours, in a setting where physicians do not always have much experience, where potential assistance (i.e. other physicians) is non-existent and where fatigue of the on-call endoscopist could play a significant role in the decision making process.

In conclusion, Hemospray ${ }^{\circledR}$ application by on-call endoscopists outside regular hours is technically feasible, primarily used for UGIB, mostly secondary to peptic ulcers and malignancy related bleeding, and mainly as a salvage therapy. Its use carries a very low risk of complication. Although recurrence and mortality rates appear to be higher as compared to previously published studies, $40.5 \%$ of our patients did not require a further intervention and were alive at day 30 of follow-up, despite being severely ill. 


\section{FIGURE LEGENDS}

Figure 1: Endoscopic portable equipment

Figure 2: Use of Hemospray depending on endoscopist experience

Figure 3: Proportion of the use of Hemospray as primary or salvage therapy in patients with cessation and ongoing bleeding

Figure 4: Survival depending on bleeding cessation after use of Hemospray 


\section{TABLES}

Table 1: Patients clinical and biological characteristics

\begin{tabular}{|c|c|}
\cline { 2 - 2 } \multicolumn{1}{c|}{} & $\mathrm{n}$ patients \\
\hline Age (years) (mean +/-SD) & $65(12.2)$ \\
\hline Sex (\%) & $107(70.4)$ \\
Female & $45(29.6)$ \\
\hline Comorbidities (\%) & $140(92)$ \\
CKD pulmonary & $80(52)$ \\
Cancer & $23(15.1)$ \\
CLD & $50(32.9)$ \\
Hereditary hemostasis disorder & $25(16.3)$ \\
Other & $5(3.3)$ \\
None & $26(17.1)$ \\
\hline Antiplatelet only ${ }^{\circ}$ & \\
Anticoagulant only ${ }^{\circ}$ & $91(59.9)$ \\
Antiplatelet \& anticoagulant combined & $21(13.8)$ \\
\hline Antiplatelet \& anticoagulant medication (\%) & $30(19.7)$ \\
Systolic BP* & $10(6.6)$ \\
\hline Heart rate** & \\
Hematemesis & $98.79(23.0)$ \\
Blood in gastric tube & $97.81(22.5)$ \\
\hline Hematochezia & $151(99.3)$ \\
Melenae & $64(42.1)$ \\
Combined & $11(7.2)$ \\
\hline Vital signs (mean +-SD) & $39(25.7)$ \\
\hline Hemoglobin serum level (g/dL)* (mean +/-SD) & $71(46.7)$ \\
\hline Number of requiered pRBC (mean +/-SD) & $38(24.8)$ \\
\hline Urea serum level (mM)** (mean +/-SD) & $64(42.1)$ \\
\hline & $7(1.5)$ \\
\hline & $142(93.4)$ \\
\hline Overt bleeding signs (\%) & $2.75(0.8)$ \\
\hline & $17.59(9.9)$ \\
\hline
\end{tabular}

SD: standard deviation; CV: cardio-vascular; CKD: chronic kidney disease; CLD: chronic liver disease; ASA:

Aspirin; BP: blood pressure; pRBC: packed red blood cells

* lowest recorded value before the endoscopy, ** highest recorded value before the endoscopy

normal $\mathrm{Hb}: 12-18 \mathrm{~g} / \mathrm{dL}$, normal urea : 3-7 mM

- Acetylsalicylic acid, Clopidogrel, Prasugrel, Ticagrelor

${ }^{\circ}$ Warfarin, Dabigatran, Rivaroxaban, Apixaban, Heparin, Fondaparinux 


\section{Table 2: Endoscopic management}

\begin{tabular}{|c|c|}
\hline & n procedures $(\%)$ \\
\hline Prior endoscopy (within 30 days prior) & $46(30.1)$ \\
\hline Prior hemostatic technics & $26(17)$ \\
\hline Epinephrine injection & 12 \\
\hline Metal clips & 8 \\
\hline Cautery*** & 4 \\
\hline Band ligation & 4 \\
\hline Glue & 0 \\
\hline Sclerotherapy & 0 \\
\hline Hemospray & 6 \\
\hline \multicolumn{2}{|l|}{ Cause of bleeding } \\
\hline PUD (Forrest Ia and Ib) & $73(47.7)$ \\
\hline Tumor & $34(22.2)$ \\
\hline Esophagitis & $19(12.4)$ \\
\hline Dieulafoy lesion & $2(1.3)$ \\
\hline Portal hypertension & $7(4.6)$ \\
\hline Vascular lesions* & $3(1.9)$ \\
\hline Post endoscopy** & $9(5.9)$ \\
\hline Ischemia (esophagus, stomach and colonic) & $8(5.2)$ \\
\hline Mallory Weiss syndrome & $1(0.7)$ \\
\hline Anastomotic bleeding & $4(2.6)$ \\
\hline Other & $4(2.6)$ \\
\hline \multicolumn{2}{|l|}{ Origin of bleeding } \\
\hline Esophagus & $35(22.9)$ \\
\hline GEJ & $10(6.5)$ \\
\hline Body of stomach & $37(24.1)$ \\
\hline Antrum & $19(12.4)$ \\
\hline Duodenal bulb & $45(29.4)$ \\
\hline Second part of the duodenum & $17(11)$ \\
\hline Other site of bleeding & $16(10.5)$ \\
\hline Multiple sites of bleeding & 23 \\
\hline \multicolumn{2}{|l|}{ Type of bleeding } \\
\hline None active & $4(2.6)$ \\
\hline Oozing & $129(84.3)$ \\
\hline Spurting & $17(11.1)$ \\
\hline Undetermined & $3(2)$ \\
\hline \multicolumn{2}{|l|}{ Hemospray use } \\
\hline Primary therapy & $60(39.2)$ \\
\hline Salvage therapy*** & $93(60.8)$ \\
\hline Difficulty during Hemospray application & $5(3.3)$ \\
\hline \multicolumn{2}{|c|}{ Other hemostatic technics during the on call urgent endoscopy } \\
\hline Total cases & 81 \\
\hline Epinephrine injection & $68(44.4)$ \\
\hline Metal clips & $38(24.8)$ \\
\hline Thermocoagulation**** & $9(5.9)$ \\
\hline Band ligation & $3(2)$ \\
\hline Glue & $1(0.7)$ \\
\hline Sclerotherapy & $0(0.0)$ \\
\hline Combined therapy & 36 \\
\hline Bleeding cessation after Hemospray application & $121(79.0)$ \\
\hline
\end{tabular}

PUD: peptic ulcer disease; GAVE: Gastric antral vascular ectasia; GEJ: gastro-esophageal junction 
* GAVE, angioectasia

** endoscopic resection, biopsy, sphincterotomy

*** salvage therapy was defined as the application of Hemospray ${ }^{\circledR}$ for persistent bleeding after failure of other hemostatic modalities either during the same endoscopic procedure or after failure of previous endoscopic attempts

**** argon plasma coagulation, and bipolar electrocautery

\section{Table 3: Patients follow-up}

\begin{tabular}{|c|c|}
\cline { 2 - 2 } \multicolumn{1}{c|}{} & $\mathrm{n}$ patients or \\
procedures (\%)
\end{tabular}

EGD: esogastroduodenoscopy, ERCP: endoscopic retrograde cholangiopancreatography

* argon plasma coagulation, and bipolar electrocautery 


\section{REFERENCES:}

1. van Leerdam ME. Epidemiology of acute upper gastrointestinal bleeding. Best Pract Res Clin Gastroenterol. 2008;22(2):209-24.

2. Hearnshaw SA, Logan RFA, Lowe D, et al. Acute upper gastrointestinal bleeding in the UK: patient characteristics, diagnoses and outcomes in the 2007 UK audit. Gut. 2011 Oct;60(10):1327-35.

3. Barkun AN, Bardou M, Kuipers EJ, et al. International consensus recommendations on the management of patients with nonvariceal upper gastrointestinal bleeding. Ann Intern Med. 2010 Jan 19;152(2):101-13.

4. de Franchis R, Baveno VI Faculty. Expanding consensus in portal hypertension: Report of the Baveno VI Consensus Workshop: Stratifying risk and individualizing care for portal hypertension. J Hepatol. 2015 Sep;63(3):743-52.

5. Gralnek IM, Dumonceau J-M, Kuipers EJ, et al. Diagnosis and management of nonvariceal upper gastrointestinal hemorrhage: European Society of Gastrointestinal Endoscopy (ESGE) Guideline. Endoscopy. 2015 Oct;47(10):a1-46.

6. Laine L, Cook D. Endoscopic ligation compared with sclerotherapy for treatment of esophageal variceal bleeding. A meta-analysis. Ann Intern Med. 1995 Aug 15;123(4):280-7.

7. Laine L, McQuaid KR. Endoscopic therapy for bleeding ulcers: an evidence-based approach based on meta-analyses of randomized controlled trials. Clin Gastroenterol Hepatol Off Clin Pract J Am Gastroenterol Assoc. 2009 Jan;7(1):33-47; quiz 1-2.

8. Sung JJY, Tsoi KKF, Lai LH, et al. Endoscopic clipping versus injection and thermocoagulation in the treatment of non-variceal upper gastrointestinal bleeding: a meta-analysis. Gut. 2007 Oct;56(10):1364-73.

9. Hwang JH, Fisher DA, Ben-Menachem T, et al. The role of endoscopy in the management of acute non-variceal upper GI bleeding. Gastrointest Endosc. 2012 Jun;75(6):1132-8.

10. Chen Y-I, Barkun AN. Hemostatic Powders in Gastrointestinal Bleeding: A Systematic Review. Gastrointest Endosc Clin N Am. 2015 Jul;25(3):535-52.

11. Hagel AF, Albrecht H, Nägel A, et al. The Application of Hemospray in Gastrointestinal Bleeding during Emergency Endoscopy. Gastroenterol Res Pract. 2017;2017:3083481.

12. Giday S, Van Alstine W, Van Vleet J, et al. Safety analysis of a hemostatic powder in a porcine model of acute severe gastric bleeding. Dig Dis Sci. 2013 Dec;58(12):3422-8.

13. Giday SA, Kim Y, Krishnamurty DM, et al. Long-term randomized controlled trial of a novel nanopowder hemostatic agent (TC-325) for control of severe arterial upper gastrointestinal bleeding in a porcine model. Endoscopy. 2011 Apr;43(4):296-9. 
14. Chen Y-I, Wyse J, Lu Y, Martel M, et al. TC-325 hemostatic powder versus current standard of care in managing malignant GI bleeding: a pilot randomized clinical trial. Gastrointest Endosc. 2019 Aug 19;

15. Chen Y-I, Barkun A, Nolan S. Hemostatic powder TC-325 in the management of upper and lower gastrointestinal bleeding: a two-year experience at a single institution. Endoscopy. 2015 Feb;47(2):167-71.

16. Commissioner $\mathrm{O}$ of the. Press Announcements - FDA permits marketing of new endoscopic device for treating gastrointestinal bleeding [Internet]. [cited 2019 Apr 5]. Available from: https://www.fda.gov/NewsEvents/Newsroom/PressAnnouncements/ucm606799.htm

17. Sung JJY, Luo D, Wu JCY, et al. Early clinical experience of the safety and effectiveness of Hemospray in achieving hemostasis in patients with acute peptic ulcer bleeding. Endoscopy. 2011 Apr;43(4):291-5.

18. Ibrahim M, El-Mikkawy A, Mostafa I, et al. Endoscopic treatment of acute variceal hemorrhage by using hemostatic powder TC-325: a prospective pilot study. Gastrointest Endosc. 2013 Nov;78(5):769-73.

19. Haddara S, Jacques J, Lecleire S, et al. A novel hemostatic powder for upper gastrointestinal bleeding: a multicenter study (the "GRAPHE" registry). Endoscopy. 2016 Dec;48(12):1084-95.

20. Alzoubaidi D, Hussein M, Rusu R, et al. Outcomes from an International Multicentre Registry of patients with acute gastrointestinal bleeding undergoing endoscopic treatment with Hemospray. Dig Endosc Off J Jpn Gastroenterol Endosc Soc. 2019 Jul 31;

21. Rodríguez de Santiago E, Burgos-Santamaria D, Pérez-Carazo L, et al. Hemostatic spray powder TC-325 for GI bleeding in a nationwide study: survival and predictors of failure via competing risks analysis. Gastrointest Endosc. 2019 Jun 17;

22. Facciorusso A, Straus Takahashi M, Eyileten Postula C, et al. Efficacy of hemostatic powders in upper gastrointestinal bleeding: A systematic review and meta-analysis. Dig Liver Dis Off J Ital Soc Gastroenterol Ital Assoc Study Liver. 2019 Aug 7;

23. Holster IL, Brullet E, Kuipers EJ, et al. Hemospray treatment is effective for lower gastrointestinal bleeding. Endoscopy. 2014 Jan;46(1):75-8.

24. Ng JL, Marican M, Mathew R. Topical haemostatic powder as a novel endoscopic therapy for severe colonic diverticular bleeding. ANZ J Surg. 2019 Mar;89(3):E56-60.

25. Ibrahim M, El-Mikkawy A, Abdel Hamid M, et al. Early application of haemostatic powder added to standard management for oesophagogastric variceal bleeding: a randomised trial. Gut. 2019;68(5):844-53. 
STROBE Statement — checklist of items that should be included in reports of observational studies

\begin{tabular}{|c|c|c|}
\hline & $\begin{array}{c}\text { Item } \\
\text { No }\end{array}$ & Recommendation \\
\hline \multirow[t]{2}{*}{ Title and abstract } & \multirow[t]{2}{*}{1} & (a) Indicate the study's design with a commonly used term in the title or the abstract \\
\hline & & $\begin{array}{l}\text { (b) Provide in the abstract an informative and balanced summary of what was done } \\
\text { and what was found }\end{array}$ \\
\hline \multicolumn{3}{|l|}{ Introduction } \\
\hline Background/rationale & 2 & Explain the scientific background and rationale for the investigation being reported \\
\hline Objectives & 3 & State specific objectives, including any prespecified hypotheses \\
\hline \multicolumn{3}{|l|}{ Methods } \\
\hline Study design & 4 & Present key elements of study design early in the paper \\
\hline Setting & 5 & $\begin{array}{l}\text { Describe the setting, locations, and relevant dates, including periods of recruitment, } \\
\text { exposure, follow-up, and data collection }\end{array}$ \\
\hline Participants & 6 & $\begin{array}{l}\text { (a) Cohort study - Give the eligibility criteria, and the sources and methods of } \\
\text { selection of participants. Describe methods of follow-up } \\
\text { Case-control study - Give the eligibility criteria, and the sources and methods of } \\
\text { case ascertainment and control selection. Give the rationale for the choice of cases } \\
\text { and controls } \\
\text { Cross-sectional study - Give the eligibility criteria, and the sources and methods of } \\
\text { selection of participants }\end{array}$ \\
\hline
\end{tabular}

(b) Cohort study — For matched studies, give matching criteria and number of exposed and unexposed

Case-control study - For matched studies, give matching criteria and the number of controls per case

\begin{tabular}{|c|c|c|}
\hline Variables & 7 & $\begin{array}{l}\text { Clearly define all outcomes, exposures, predictors, potential confounders, and effect } \\
\text { modifiers. Give diagnostic criteria, if applicable }\end{array}$ \\
\hline $\begin{array}{l}\text { Data sources/ } \\
\text { measurement }\end{array}$ & $8^{*}$ & $\begin{array}{l}\text { For each variable of interest, give sources of data and details of methods of } \\
\text { assessment (measurement). Describe comparability of assessment methods if there } \\
\text { is more than one group }\end{array}$ \\
\hline Bias & 9 & Describe any efforts to address potential sources of bias \\
\hline Study size & 10 & Explain how the study size was arrived at \\
\hline Quantitative variables & 11 & $\begin{array}{l}\text { Explain how quantitative variables were handled in the analyses. If applicable, } \\
\text { describe which groupings were chosen and why }\end{array}$ \\
\hline \multirow[t]{5}{*}{ Statistical methods } & \multirow[t]{5}{*}{12} & (a) Describe all statistical methods, including those used to control for confounding \\
\hline & & (b) Describe any methods used to examine subgroups and interactions \\
\hline & & (c) Explain how missing data were addressed \\
\hline & & $\begin{array}{l}\text { (d) Cohort study - If applicable, explain how loss to follow-up was addressed } \\
\text { Case-control study-If applicable, explain how matching of cases and controls was } \\
\text { addressed }\end{array}$ \\
\hline & & $\begin{array}{l}\text { Cross-sectional study —If applicable, describe analytical methods taking account of } \\
\text { sampling strategy }\end{array}$ \\
\hline
\end{tabular}

(e) Describe any sensitivity analyses

Continued on next page 


\section{Results}

\begin{tabular}{|c|c|c|}
\hline \multirow[t]{3}{*}{ Participants } & \multirow[t]{3}{*}{ 13* } & $\begin{array}{l}\text { (a) Report numbers of individuals at each stage of study — eg numbers potentially eligible, } \\
\text { examined for eligibility, confirmed eligible, included in the study, completing follow-up, and } \\
\text { analysed }\end{array}$ \\
\hline & & (b) Give reasons for non-participation at each stage \\
\hline & & (c) Consider use of a flow diagram \\
\hline \multirow[t]{3}{*}{$\begin{array}{l}\text { Descriptive } \\
\text { data }\end{array}$} & \multirow[t]{3}{*}{$14 *$} & $\begin{array}{l}\text { (a) Give characteristics of study participants (eg demographic, clinical, social) and information } \\
\text { on exposures and potential confounders }\end{array}$ \\
\hline & & (b) Indicate number of participants with missing data for each variable of interest \\
\hline & & (c) Cohort study-Summarise follow-up time (eg, average and total amount) \\
\hline \multirow[t]{3}{*}{ Outcome data } & \multirow[t]{3}{*}{$15^{*}$} & Cohort study—Report numbers of outcome events or summary measures over time \\
\hline & & $\begin{array}{l}\text { Case-control study-Report numbers in each exposure category, or summary measures of } \\
\text { exposure }\end{array}$ \\
\hline & & Cross-sectional study —Report numbers of outcome events or summary measures \\
\hline \multirow[t]{3}{*}{ Main results } & \multirow[t]{3}{*}{16} & $\begin{array}{l}\text { (a) Give unadjusted estimates and, if applicable, confounder-adjusted estimates and their } \\
\text { precision (eg, } 95 \% \text { confidence interval). Make clear which confounders were adjusted for and } \\
\text { why they were included }\end{array}$ \\
\hline & & (b) Report category boundaries when continuous variables were categorized \\
\hline & & $\begin{array}{l}\text { (c) If relevant, consider translating estimates of relative risk into absolute risk for a meaningful } \\
\text { time period }\end{array}$ \\
\hline Other analyses & 17 & $\begin{array}{l}\text { Report other analyses done—eg analyses of subgroups and interactions, and sensitivity } \\
\text { analyses }\end{array}$ \\
\hline \multicolumn{3}{|l|}{ Discussion } \\
\hline Key results & 18 & Summarise key results with reference to study objectives \\
\hline Limitations & 19 & $\begin{array}{l}\text { Discuss limitations of the study, taking into account sources of potential bias or imprecision. } \\
\text { Discuss both direction and magnitude of any potential bias }\end{array}$ \\
\hline Interpretation & 20 & $\begin{array}{l}\text { Give a cautious overall interpretation of results considering objectives, limitations, multiplicity } \\
\text { of analyses, results from similar studies, and other relevant evidence }\end{array}$ \\
\hline Generalisability & 21 & Discuss the generalisability (external validity) of the study results \\
\hline
\end{tabular}

\section{Other information}

Funding 22 Give the source of funding and the role of the funders for the present study and, if applicable, for the original study on which the present article is based

*Give information separately for cases and controls in case-control studies and, if applicable, for exposed and unexposed groups in cohort and cross-sectional studies.

Note: An Explanation and Elaboration article discusses each checklist item and gives methodological background and published examples of transparent reporting. The STROBE checklist is best used in conjunction with this article (freely available on the Web sites of PLoS Medicine at http://www.plosmedicine.org/, Annals of Internal Medicine at http://www.annals.org/, and Epidemiology at http://www.epidem.com/). Information on the STROBE Initiative is available at www.strobe-statement.org. 


\section{HIGHLIGHTS}

- Real life use of the hemostatic powder Hemospray ${ }^{\circledR}$, in the setting of urgent endoscopic procedures performed outside working hours, by mobile on-call endoscopists, has yet to be described.

- The use of Hemospray ${ }^{\circledR}$ by our group was stable after becoming available and did not increase with the endoscopists experience.

- Hemospray ${ }^{\circledR}$ was mostly used for upper GIB (95.0\%), nearly half of which were due to PUD (47.7\%).

- Hemospray ${ }^{\circledR}$ was used as salvage therapy in $60.8 \%$ of cases. During follow up, $39.9 \%$ had a recurrence. At 30 days of follow-up, the mortality rate was $28.4 \%$.

- $40.5 \%$ of our patients did not require a further intervention and were alive at day 30 of follow-up, despite being severely ill. 


\section{Declaration of interests}

The authors declare that they have no known competing financial interests or personal relationships that could have appeared to influence the work reported in this paper.

$\bigotimes$ The authors declare the following financial interests/personal relationships, which may be considered as potential competing interests:

Dr Marine Camus is a consultant for Boston Scientific and Cook Medical.

Dr Xavier Dray has acted as a consultant for Alfasigma, Bouchara Recordati, Boston Scientific, Fujifilm, Medtronic, and Pentax. Author Xavier Dray is also cofounder and shareholder of company Augmented Endoscopy.

Dr Maximilien Barret is a consultant for Norgine and Medtronic.

Drs Aymeric Becq, Charles Houdeville, My-Linh Tran Minh, Nils Steuer, David Danan, Marie Anne Guillaumot, Einas Abou Ali, Aurélien Amiot, Nicolas Carbonell, Philippe Marteau and Ulriikka Chaput have no conflicts of interest or financial ties to disclose. 


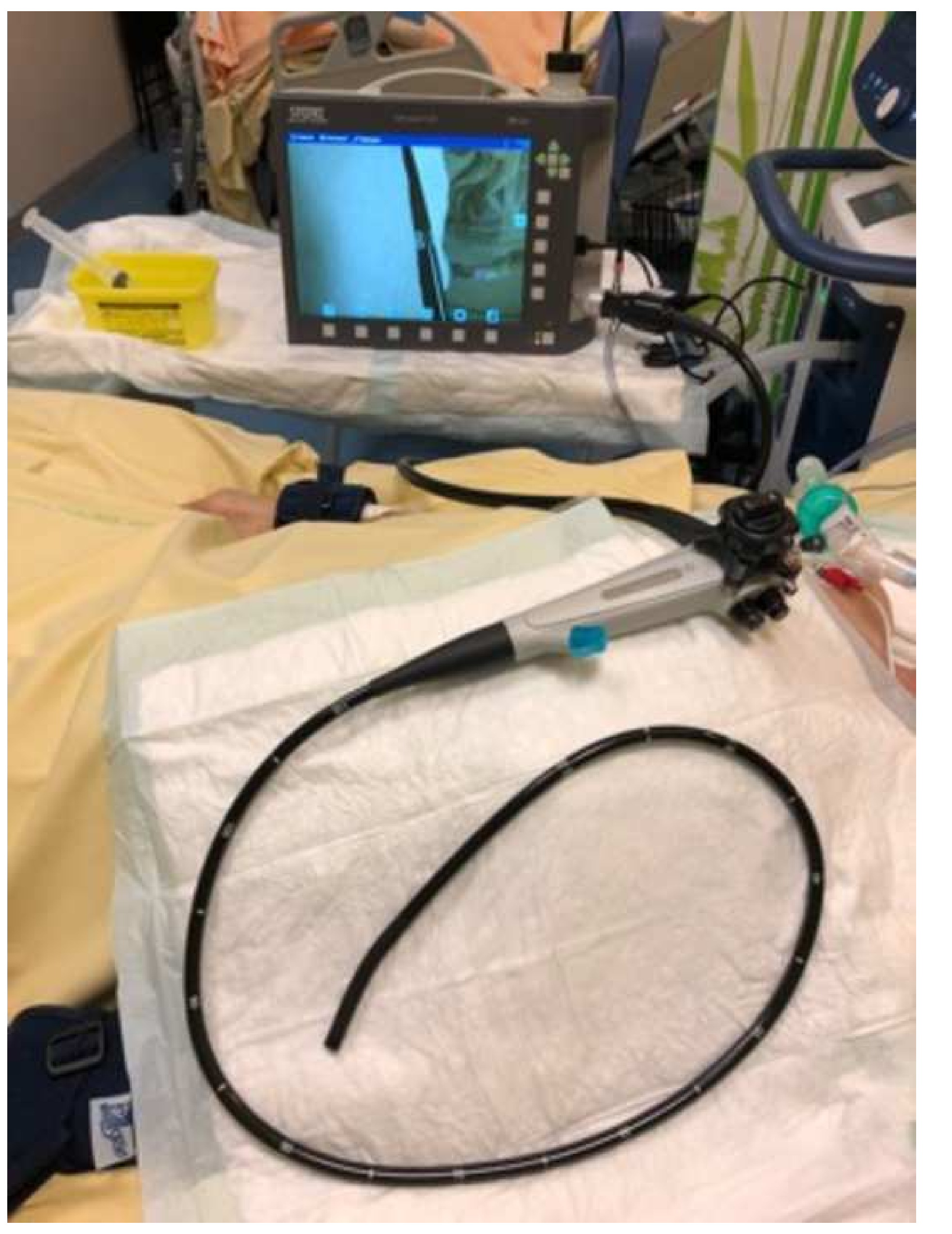

\section{.}

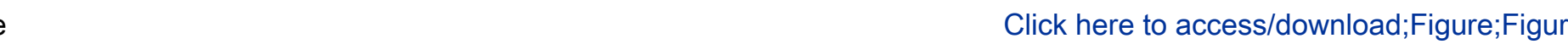




\section{FIGURE 2: Use of Hemospray depending on endoscopist experience}

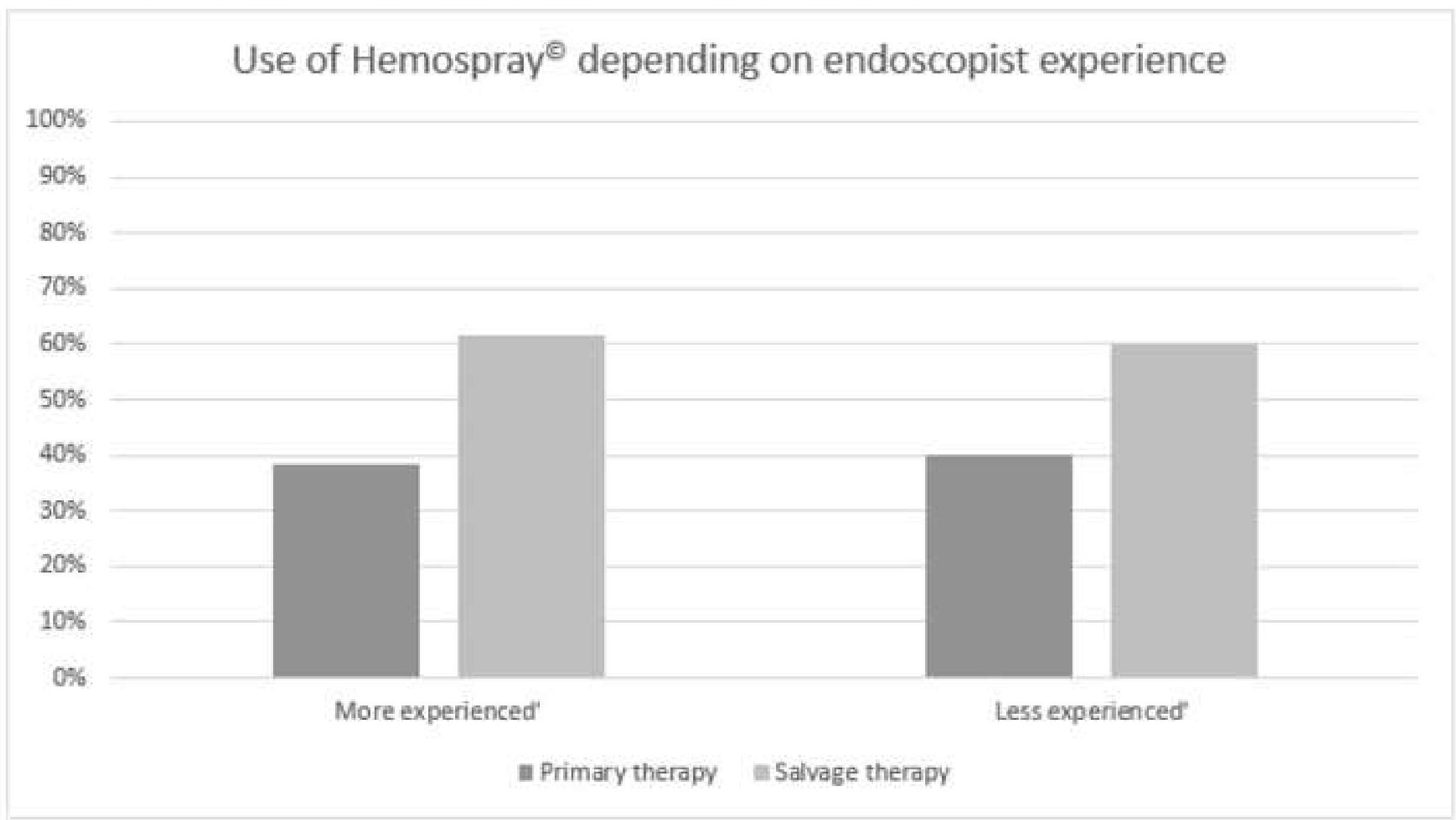


FIGURE 3: Proportion of the use of Hemospray as primary or salvage therapy in patients with cessation and ongoing bleeding

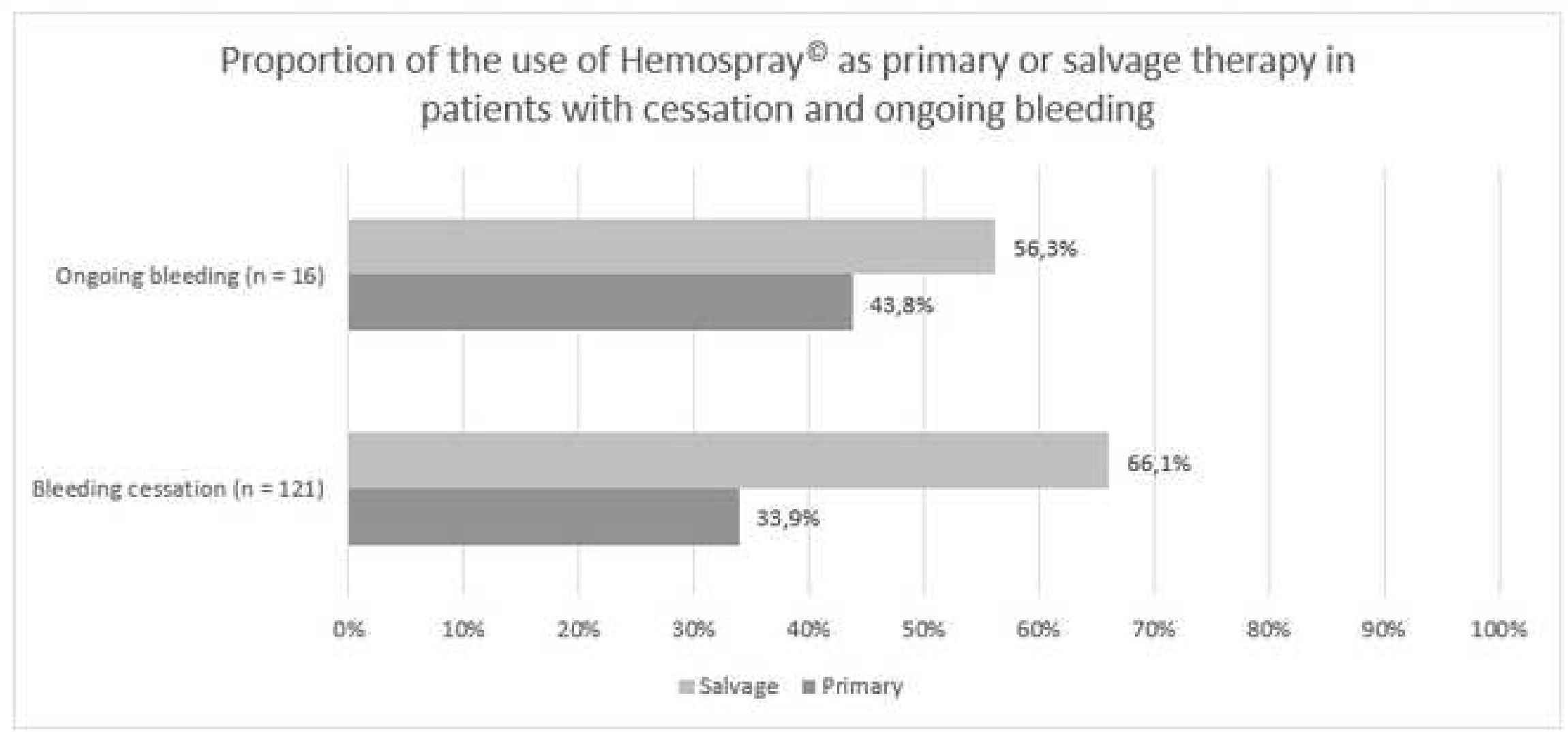

Proportion of the use of Hemospray ${ }^{\circ}$ as primary or salvage therapy in patients with cessation and ongoing bleeding 


\section{FIGURE 4: Survival depending on bleeding cessation after use of Hemospray}

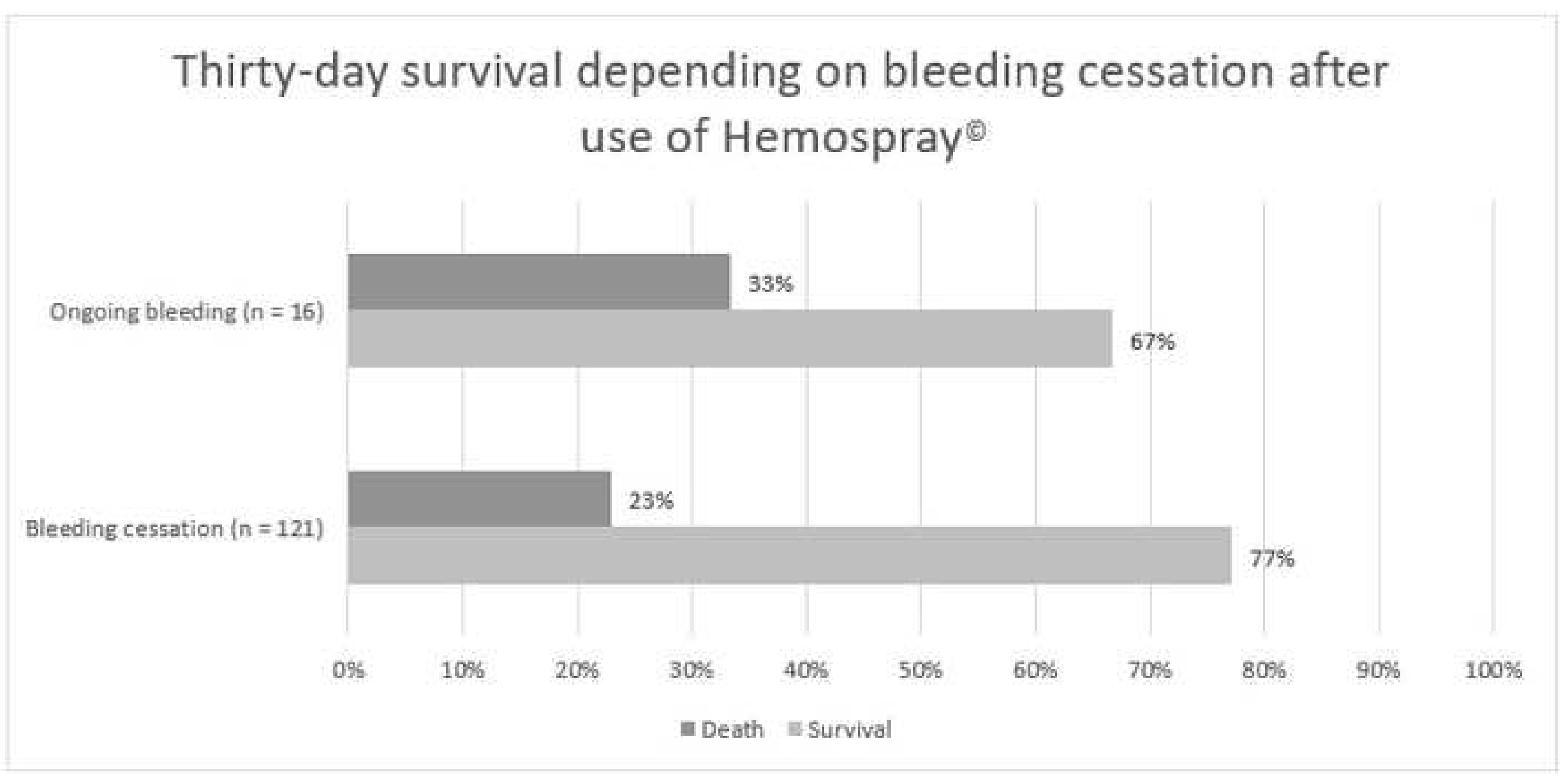

Thirty-day survival depending on bleeding cessation after use of Hemospray ${ }^{\oplus}$ 


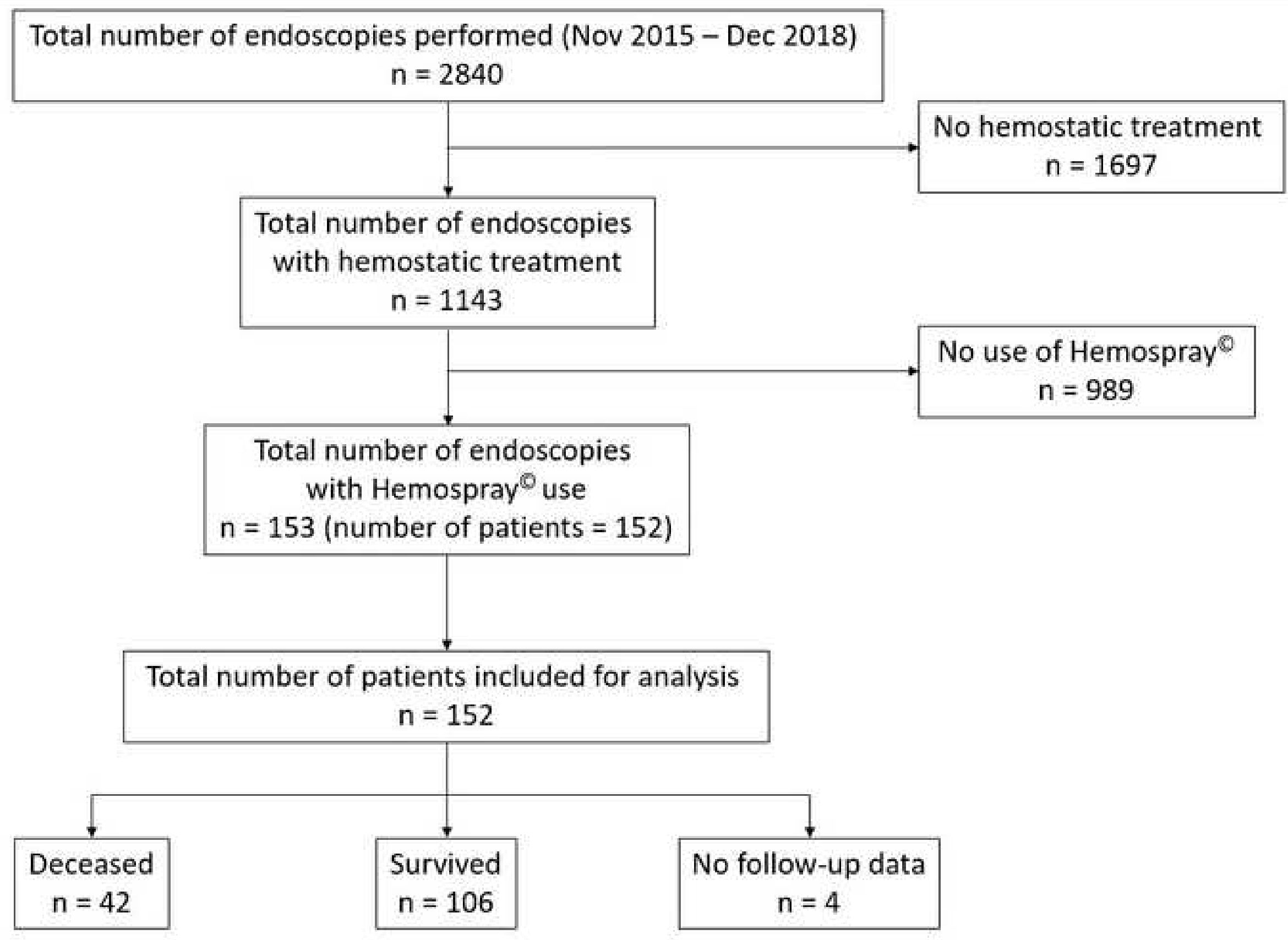

number of endoscopies

with Hemospray use

$n=106$

$\mathrm{n}=4$ 